\title{
Effect of air Recirculation on Moisture Removal Efficiency in Combined Hydrolytic-Aerobic Rotary Bio-Drying Process
}

\author{
Khajon Somsai ${ }^{1}$, Tusanee Tondee ${ }^{1}$ and Somrat Kerdsuwan ${ }^{2}$ \\ ${ }^{1}$ Rattanakosin College for Sustainable Energy and Environment (RCSEE) Rajamangala University of Technology Rattanakosin, Nakhon \\ Pathom 73170, Thailand \\ ${ }^{2}$ Department of Mechanical and Aerospace Engineering King Mongkut's University of technology North Bangkok Bangkok 10800, Thailand
}

\begin{abstract}
Rotary bio-drying is the process to reduce moisture from Municipal Solid Waste (MSW) by using the heat from aerobic bio-degradation. This study aimed to investigate the effects of air recirculation on moisture removal efficiency in combined hydrolytic-aerobic rotary bio-drying process for drying high initial moisture content MSW, allowing satisfied moisture content to convert a waste into biofuel energy. The results from the laboratory scale experiments were indicated that increasing the exhaust air recirculation ratio, more moisture increased in the end product. However, while the air recirculation ratio was equals or greater than $50 \%$, the moisture content of the end product was not significant different.
\end{abstract}

\section{Introduction}

Most of MSW for small municipality in Thailand was disposed in non-regulated open dump. Only $9.4 \%$ of the MSW generated was recycled while about $10 \%$ of the MSW in Thailand was properly treated in sanitary landfills and other proper technology facilities [18] that may be cause of the outbreak of the gastrointestinal disease and the environmental problem. MSW was generally characterized as high water content (up to $75 \%$ ) due to the relatively high proportion of food waste over $60 \%$. High water content will reduce the efficiency of energy recovery from their direct combustion in incinerator and reduce the ability for mechanical sorting utilization.

Bio-drying technology goal is to improve the quality of MSW by relying on the heat generated from the decomposition of organic matter, microbes in the reactor to reduce the moisture content of the waste $[9,10]$, while preserving calorific value [1]. After a bio-drying process, the MSW can be used as a source of solid fuel $[1,13]$. Moisture content was reducing form MSW without the use of fossil fuels and offers minimal power consumption that suitable for safe and economical combustion in a biomass boiler by bio-drying process [7]. It was a significant alternative way for treating MSW [11], which a good solution to reduce the amount of water and converted a waste into energy (Refuse Derived Fuel; $\mathrm{RDF}$ ) for solved the energy recovery problem from high water content of MSW.

The moisture content in the MSW was reduced through two main steps: (1) water molecules evaporate from the surface of MSW into the surrounding air by change of phase from liquid phase to gas phase ; and (2) Then removed the evaporated water from the MSW pile by the air for the exhaust gases [13]. Limited amounts of free water may seep through the MSW pile and be collected at the bottom of the bio-drying reactor as leachate [11].

The air flow was influence the temperature biomasses drying process, while the level of decomposition of organic matter degradation affects the calorific value and stability of the final product [1]. The daily inversion of airflow could achieve MSW drying in very short times (8-9 days) and leads to a homogeneous final product [13]. Zhang $[16,17]$ improved the moisture and accelerated the decomposition of waste with high moisture content by increasing the circulating leachate during hydrolytic degradation prior to aerobic decomposition. There were a few studies in aerobic rotary bio-drying reactor of MSW $[2,12,14,15]$. Khajon [5] reported that combined hydrolytic-aerobic in rotary bio-drying process could produce homogeneous RDF from MSW. It was also found that the increased airflow rate was not linearly proportional to the weight loss. With the first 2 days of hydrolytic stage before supplied high air flow in aerobic stage could more increase moisture removal efficiency for rotary bio-drying process than increase double air flow rate only [5].

The main objective of this study was to investigate the effect of direct air recirculation on moisture removal in combined hydrolytic-aerobic rotary bio-drying for high moisture content MSW, allowing to be obtain biofuel of satisfactory energy content.

\section{Methods}




\subsection{Characteristics of MSW feedstock}

The raw MSW was collected from dumping area the Administrative Organization of Tumbon (AOT) Kaerai, kratumban samutsakorn province, Thailand. The raw MSW was grinded by hammer mill then sorted with screening size $50 \mathrm{~mm}$. The remains on the screen were collected for preparing feedstock and the grinded MSW which smaller than $50 \mathrm{~mm}$ were rejected. The bulky waste such as carpet, yard waste whose size that bigger than $250 \mathrm{~mm}$ was rejected by hand. Only MSW size between $50-250 \mathrm{~mm}$ was used as feedstock for laboratory process.

\subsection{Experimental equipment setup}

The MSW feedstock was filled until the half of reactor which the total weight approximately $250 \mathrm{~kg}$. The retention time of bio-drying process was 8 days [2]. The reactor turning frequency was fixed at $1.5 \mathrm{rpm}$. Air was supplied into the reactor at the centre core shaft of horizontal tank reactor by air blower.

The scheme of the laboratory scale rotary bio-drying process used for developing the experiment was presented in Figure 1.

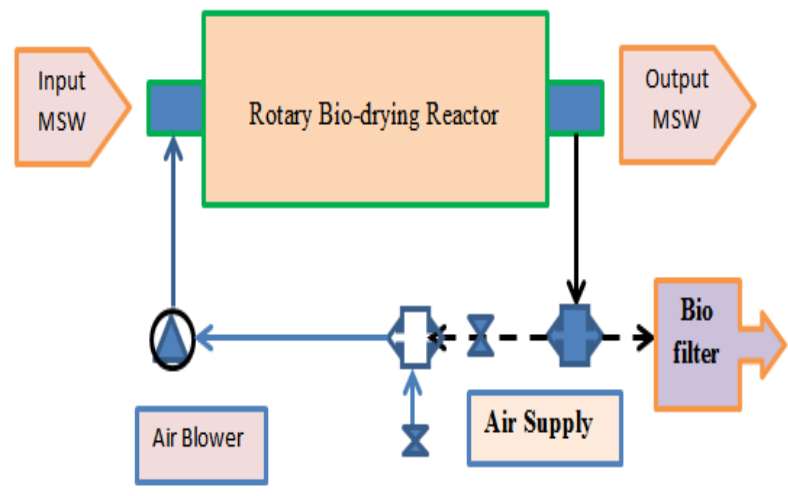

Figure 1. Scheme of the Rotary bio-drying Process

The temperature and humidity of inlet and outlet air were measured twice a day by humidity/temperature meter model DIGICON HT-776.

The temperature of composting biomass and inner reactor was continuously monitored in every 15 minutes by using digital thermometer which installed at three different locations inside the reactor; at its centre and at its two ends. The experimental data was recorded by data logger.

The experiment operation was consists of two stages; the hydrolytic and the aerobic stages. Which automatically controlled by a timer program. For hydrolytic stage, the reactor was only rotate without aeration and the operating period was 2 day. Following by aerobic stage with ventilation frequency at 48 times/ day (run 20 minute, stop 10 minute) and the operating period was 6 day. The air recirculation ratio $0 \%, 25 \%$, $50 \%, 75 \%$ and $100 \%$ respectively, was investigated.

\subsection{Sampling, Parameter Analysis and Statistic Analysis}

A $100 \mathrm{~g}$ of samples were collected from three different locations, mainly from the mid span and two end terminals of the reactor, using a composite sampling method to minimize disturbance of the adjacent materials.

The samples were dried in an oven at $105^{\circ} \mathrm{C}$ for $24 \mathrm{hr}$. in order to determine their moisture content following the ISO5068-1 standard.

Statistical analysis was performed using ANOVA. Test for significant difference in each condition were defined by $\mathrm{P}<0.05$.

\section{Results and discussions}

\subsection{Moisture content and moisture removal efficiency}

The results were showed in the form of moisture content and the moisture removal efficiency of the trial. The results of the moisture content for five different constructional solutions were presented.

Table 1. The rotary bio-drying experiment results

\begin{tabular}{|c|c|c|c|c|c|}
\hline Trial & $\begin{array}{c}\text { Air recirculation } \\
\text { ratio \% }\end{array}$ & \multicolumn{2}{|c|}{$\begin{array}{c}\text { Hydrolytic } \\
\text { Stage } \\
\text { moisture } \\
\text { content } \%\end{array}$} & \multicolumn{2}{|c|}{$\begin{array}{c}\text { Aerobic } \\
\text { Stage } \\
\text { moisture } \\
\text { content } \%\end{array}$} \\
\cline { 2 - 6 } & & Initial & Final & Initial & Final \\
\hline A & $0 \%$ & 64.7 & 62.2 & 52.6 & 18.6 \\
\hline B & $25 \%$ & 74.6 & 72.1 & 61.5 & 27.1 \\
\hline C & $50 \%$ & 73.2 & 70.6 & 65.4 & 29.5 \\
\hline D & $75 \%$ & 71.9 & 68.4 & 63.3 & 32.7 \\
\hline E & $100 \%$ & 70.6 & 66.2 & 61.2 & 35.8 \\
\hline
\end{tabular}

All trials moisture content were decreasing, trial A, B, $\mathrm{C}, \mathrm{D}$ and $\mathrm{E}$, from $64.7 \%$ to $19.6 \%, 74.6 \%$ to $27.1 \%$, $73.2 \%$ to $29.5 \%, 71.9 \%$ to $32.7 \%$ and $70.6 \%$ to $35.8 \%$, respectively. From the results, all trials show the percentage of moisture content reduced to lower than $50 \%$. However, only the final product for trial A showed the acceptance percentage for RDF or energy purposes which is less than $25 \%$. The end products for reactor B to $\mathrm{E}$ did not achieve RDF requirements [8] as showed in Table 1. 


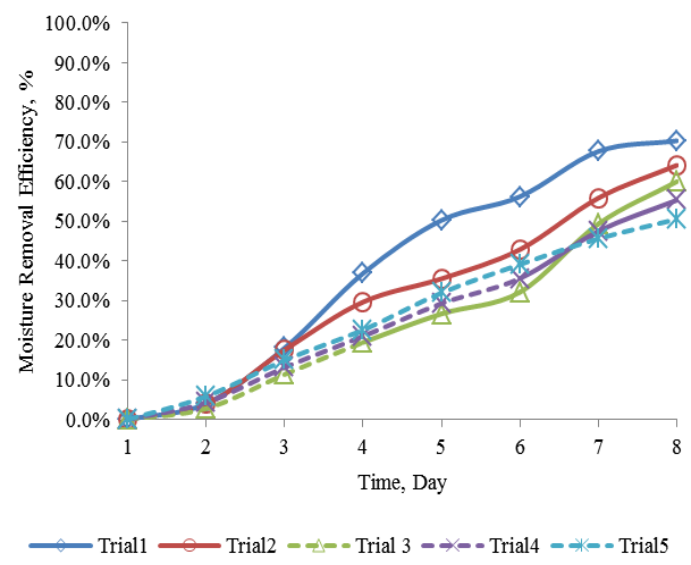

Figure 2. The moisture removal efficiency

Fig. 2, showed the moisture removal efficiency of trial A to E. The moisture removal efficiency for rotary bio-drying with combined hydrolytic and aerobic process was higher more than $50.0 \%$ on $8^{\text {th }}$ day trial. Only the operation condition without air recirculation can achieved the moisture content below $25 \%$. This condition proved that air ventilation or aeration was playing the important role for bio-drying assistance. The more increased direct air recirculation ratio was more decreased the moisture removal efficiency and more moisture content in the end product inversely.

\subsection{Temperature and relative humidity}

The temperature was the key parameter for water evaporation and organics degradation in bio-drying process. During the hydrolytic stage, the temperatures inside the reactor were higher than the ambient air temperature about $1-5{ }^{\circ} \mathrm{C}$. The temperatures in the aerobic stage were inversely proportional to the temporal span time of the hydrolytic stage.

Trial A, a combined hydrolytic-aerobic bio-drying without air recirculation for the first 2 days of operation, the exhaust temperature and relative humidity were higher than ambient temperature and relative humidity, respectively. The exhaust relative humidity was declined when the air was supplied to the reactor (Fig. 3(a)).

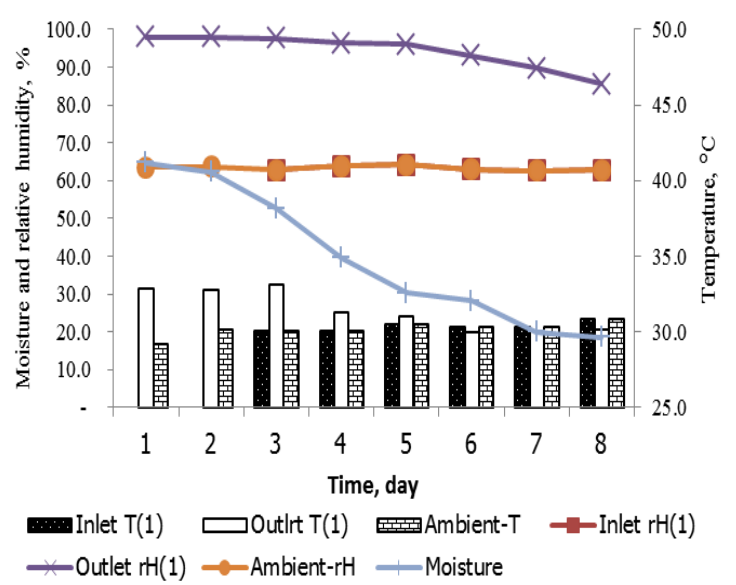

Figure 3(a) Temperature, Moisture and relative humidity profile of Trial A

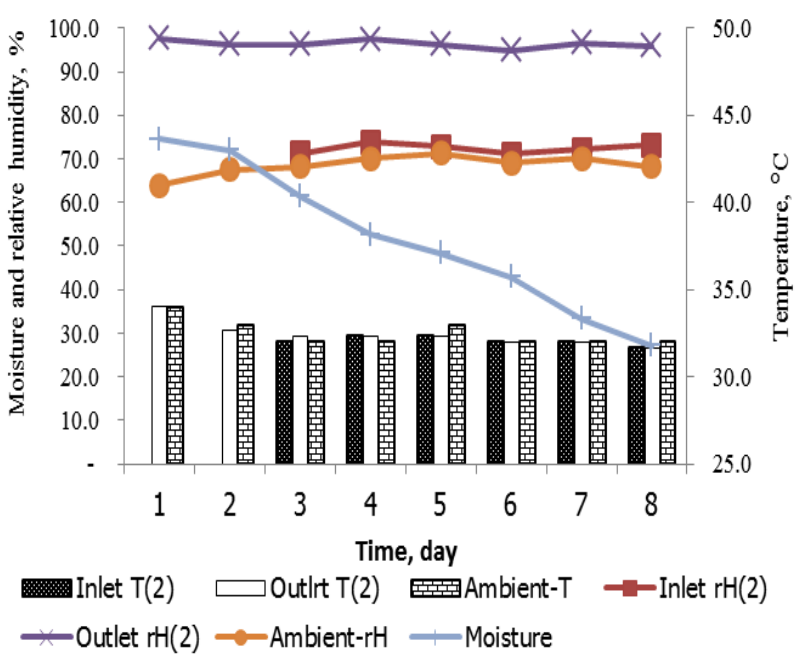

Figure 3(b) Temperature, Moisture and relative humidity profile of Trial B

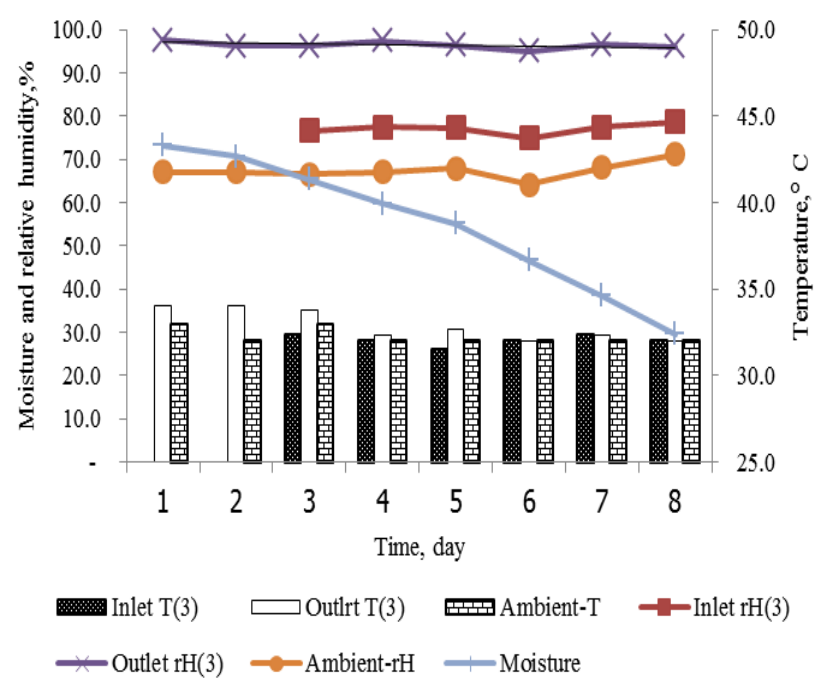

Figure 3(c) Temperature, Moisture and relative humidity profile of Trial C

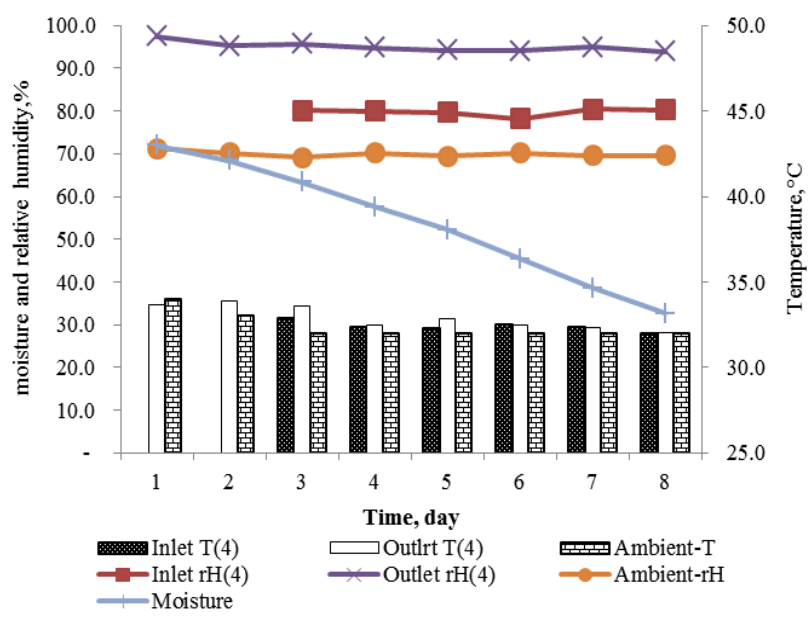

Figure 3(d) Temperature, Moisture and relative humidity profile of Trial D 
The proper moisture content for decomposing was between $40 \%-60 \%$ and the highest decomposition rate was achieved at $50 \%$ of moisture content $[4,6]$. At Trial A, the moisture content was higher than $40 \%$ within 4 days of operation and decreasing based on the daily rotation the rotary drum and supply air without recirculation (Figure 3a). For Trial B to E that operated with air recirculation, the moisture content was higher than $40 \%$ for a long time that proper for organic decomposition process.

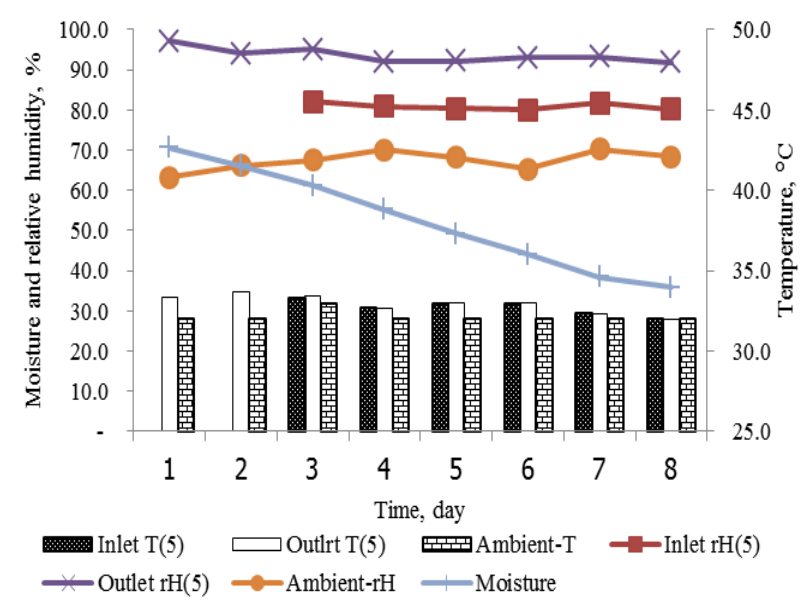

Figure 3(e) Temperature, Moisture and relative humidity profile of Trial E

For Figure $3 \mathrm{~b}$ to $3 \mathrm{e}$, an inlet relative humidity was higher than ambient relative humidity. An inlet relative humidity was decreased when increased the recirculation ratio. The exhaust relative humidity was stable when supplied the air recirculation into the reactor. The moisture content was decreased inversely of recirculation ratio increase.

Exhaust gas leave from rotary bio-drying process will be near saturated and almost the same temperature of reactor. If the difference between inlet and outlet air was greater than $25^{\circ} \mathrm{C}$, the relative humidity of inlet air will a minor effect in determining overall moisture removal. The relative humidity will be increased base on recirculation ratio due to the high relative humidity of exhaust air. According to increasing of inlet relative humidity, the difference between inlet and exhaust air will be decreased while the moisture removal efficiency was decreased. Although the different of an inlet and exhaust air temperature and relative humidity were little. However, the drying process in rotary bio-drying could be occurred even in high inlet relative humidity. That was consistent with studied of Huag [3] which the drying could be occurring even in climate with high ambient humidity in air. Drying time increase slightly for $8-12 \%$ with recirculating $50 \%$ when exhaust air higher than ambient air at $15^{\circ} \mathrm{F}\left(8.33{ }^{\circ} \mathrm{C}\right)$ [21].

Inversely, if there was added some the energy into the reuse air in mixing proportions superior to $10 \%$ increased the thermal efficiency [19]. The evaporation rate for the airflow rate control trials was in average $15 \%$ higher compared to the conventional process, which indicates that the airflow rate control could be used to enhance also the performance of the dryer [20].

\section{Conclusions}

The effects of air recirculation on moisture removal efficiency in combined 2 days hydrolytic- 6 days aerobic rotary bio-drying process for drying high initial moisture content MSW was observed in this work. The air recirculation ratio was $0 \%, 25 \%, 50 \%, 75 \%$ and $100 \%$. The moisture content of the end product was $18.6 \%$, $27.1 \%, 29.5 \%, 32.7 \%$ and $35.8 \%$, respectively. While increasing the exhaust air recirculation ratio, more moisture increases in the end product. However, while the air recirculation ratio was greater than or equals to $50 \%$, the moisture content in the end product did not has significant different. Only the operation condition without air recirculation can achieved the moisture content below $25 \%$ for RDF standard. When recirculate the exhaust air with a high relative humidity, moisture content of the end product did not meet the requirement of RDF standard.

\section{References}

1. Adani, F., Baido, D., Calcaterra, E., Genevini, P., Bioresource Technology. 83 (2002)

2. Bartha, B.K., PhD Thesis, Technische Universität Dresden, Dresden, (2008)

3. Haug RT, Practical Handbook of Compost Engineering, Lewis Publisher, 1993

4. Jolanun B1, Tripetchkul S, Chiemchaisri C, Chaiprasert P, Towprayoon S., Environ Technol, 26(2005)

5. Khajon S, Tusanee $\mathrm{T}$, Somrat $\mathrm{K}$, Journal of Teknologi, 78 (2016)

6. Nabam Rich, Ajay Bharti, International Research Journal of Engineering and Technology (IRJET), 02(2015)

7. Navaee-Ardeh S, Bertrand F, Stuar P R, Bioresource Technology, 101(2010)

8. NA Ab Jalil, H Brasri, NE Ahmad Basri, Mohammed FM. Abushammala, Environmental Engineering Resource, 21(2016)

9. Rada E.C., Ragazzi M., Panaitescu V., UPB Scientific Bulletin, Series D: Mech.Eng., 71(2009)

10. Sadaka S, Van Devender K, Costello T, Sharara M, University of Arkansas Division of Agriculture. 2010

11. Shao L M, Ma Z H, Zhang H, Zhang D Q, He P H, Waste Management, 30(2010)

12. Skourides, I., Theophilou, C., Loizides, M., Hood, P., Smith, S.R., Waste 2006-41 Sustainable waste and resource management, Stratford-upon-Avon, UK 1921 September 2006

13. Sugni, M., Calcaterra, E., Adani, F., Bioresource Technology 96( 2005)

14. Velis C A, Longhurst P J, Drew G H, Smith R, Pollard S T J, Bioresource Technology, 100(2009)

15. Zawadzka A, Krzystek L, Ledakowicz S, Chemical Papers, 64(2010) 
16. Zhang D Q, He P J, Shao L M, Jin T F, Han JY, Journal of Environmental Sciences, 20(2008)

17. Zhang D Q, He P J, Yu L Z, Shao L M, Bioresource Technology, 100(2009)

18. Cherdsatirkul C, Earth Engineering Center Columbia University, (2012)
19. Juliana T. C. L. Toneli, Lucas B. Monteiro, Marco Aurelio J. Briso, Deovaldo Moraes Jr, Chemical Engineering Transactions, 32(2013)

20. T. Jokiniemi, T. Oksanen and J. Ahokas, Agronomy Research 13(1), 89-94, 2015

21. Jim Young, Jim Thompson and Tom Rumsey, SunDiamond Grower, (1981) 